УДК

\title{
ПЛАНАРНАЯ ТРЕХДИАПАЗОННАЯ ЧАСТОТНО-СЕЛЕКТИВНАЯ ПОВЕРХНОСТЬ С ПЕРЕДАЧЕЙ В S- И ОТРАЖЕНИЕМ В КА/КU-ДИАПАЗОНАХ
}

\author{
ГАРИМА БХАРТИ ${ }^{1}$, КУМУД РАНДЖАН ДЖА ${ }^{2}$, Г.СИНГХ ${ }^{1}$, РАДЖИВ ДжЬОТИ $^{3}$ \\ ${ }^{1}$ Университет информационных технологий им. Дюээйи, \\ Индия, Уэйкнагат, Химачал-Прадеш \\ ${ }^{2}$ Университет им. Шри Мата Ваишно Деви, \\ Индия, Катра, Джамму и Каммир \\ ${ }^{3}$ Индийская организачия космических исследований, \\ Индия, Ахмадабад
}

\begin{abstract}
Аннотация. Проведены анализ и моделирование элементарной ячейки новой низкопрофильной однослойной трехдиапазонной частотно-селективной поверхности FSS (frequency selective surface), которая состоит из двух концентрических модифицированных круговых колец. Она может использоваться в системах спутниковой связи и применяться для экранирования от электромагнитных излучений. Предлагаемая структура разработана с использованием модификаций концентрических круговых колец FSS для получения значительной относительной ширины полосы частот и стабильной частотной характеристики в случаях перпендикулярной $(T E)$ и параллельной $(T M)$ поляризаций электромагнитной волны для углов падения до $50^{\circ}$. Выполнено сравнение поляризационной и угловой стабильностей предлагаемой структуры FSS c другими структурами, представленными в научных публикациях
\end{abstract}

Ключевые слова: трехдиапазонная FSS; низкопрофильная структура; угловая стабильность; поляризационная стабильность; относительная ширина полосы частот; спутниковая связь

\section{1. ВВЕДЕНИЕ}

Частотно-селективная поверхность FSS (frequency selective surface) — это периодическая структура, состоящая из одно- или двухмерной решетки, которая функционирует как аналоговый пространственный фильтр и которая широко используется в спутниковой связи, антенных обтекателях, ракетах и электромагнитных экранах [1]. Для удовлетворения растущих потребностей многофункциональности антенн и фильтров, применяемых в системах связи/обнаружения следующего поколения, существует необходимость в разработке структуры FSS с многополосными частотными характеристиками $[2,3]$.

Существуют различные методы получения многодиапазонных частотных характеристик, такие как использование слоистых/многоярусных FSS [4, 5], фрактальных/закрученных FSS [6-9], неоднородных однослойных FSS [10], FSS на основе многорезонансных

* Авторы выражают благодарность Индийской организации космических исследований.

Работа выполнена в рамках ее проекта No. ISRO/RES/4/579/10-11. 